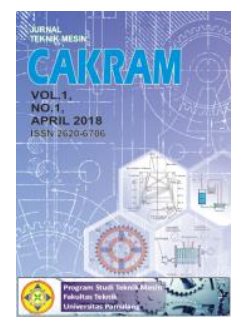

\title{
ANALISA PENGARUH PENAMBAHAN INSULATED CORE PADA SISTEM RISER LOW PRESSURE DIE CASTING ( LPDC ) UNTUK MEREDUKSI CACAT COR PRODUK KRAN DENGAN SIMULASI SOFTWARE
}

\author{
Mohamad Nasrun $^{1}$ \\ ${ }^{1}$ Program Studi Teknik Mesin, Universitas Pamulang, Jl. Surya Kencana No. 1, Tangerang Selatan, Indonesia \\ E-mail : m.nasrun.74@gmail.com
}

Masuk : 05 September 2018

Direvisi : 02 Oktober 2018

Disetujui : 03 Oktober 2018

\begin{abstract}
Abstrak: Simulasi pengecoran adalah metode yang sangat baik untuk dapat melihat penuangan logam cair pada cetakan, proses pembekuan dan pendinginan, dan memprediksi letak cacat yang akan terjadi seperti penyusutan, porositas, lubang. Penelitian ini bertujuan untuk menganalisa dan membuat desain sistem buangan Low Pressure Die Casting produk kran untuk mereduksi kebocoran akibat cacat lubang. Metode yang digunakan dengan Finite Element Method (FEM). Melakukan observasi proses low pressure die casting untuk produk kran dan membuat desain system buangan/riser dengan menggunakan Uni Grafic NX 10 dan mensimulasikan dengan Magma Soft 5.3. Hasil simulasi diamati sehingga diketahui letak cacat yang terjadi dan membuat desain yang baru agar didapat hasil yang maksimal. Hasil simulasi yang diamati ada daerah yang mengalami pembekuan lebih awal sehingga dapat mengakibatkan lubang dan porositas. Penambahan insulated core pada system riser menjadi solusi yang tepat untuk meminimalisasi cacat lubang dan porositas yang ada. Daerah yang mengalami pembekuan lebih awal dikenakan suhu yang lebih tinggi dari logam kuningan cair sehingga daerah tersebut lebih lama membeku dan terjadi pembekuan yang terarah.
\end{abstract}

Kata kunci: Simulasi, lubang, porositas, pembekuan awal, sistem buangan / riser, Insulated core

\begin{abstract}
Casting simulation is an excellent method to be able to see pouring molten metal in the mold, solidification and cooling process, and predicts the location of defects that will occur such as shrinkage, porosity, inclusions, holes.This study aims to analyze and make product design duct system for low pressure die casting product faucets to reduce leakage due to defective hole. The method used by the finite element method (FEM). Observation of low pressure die casting process for product faucets, making the design of the duct system using Uni Grafic NX 10 and simulate with Magma Soft 5.3. Simulation results were observed so that the location of the defect occurred and create a new design in order to obtain maximum results. Simulation results observed there are areas that experience premature solidification so that it can produce holes and porosity. The addition of an insulated core to the riser system becomes the perfect solution to minimize any hole defects and porosity. Areas that are subjected to premature solidification are subjected to higher temperatures than molten brass metals so that the area frozen longer and there is directional clotting.
\end{abstract}

Keywords: Simulation, hole, porosity, initial freezing, exhaust system / riser, Insulated core 


\section{PENDAHULUAN}

Permintaan pasar akan produk logam cor yang prospektif dan luas ini, kurang diimbangi dengan peningkatan kualitas produk yang dihasilkan sehingga banyak kita jumpai produk dengan kualitas yang rendah yakni banyaknya cacat yang timbul pada produk cor. salah satu pabrik yang memproduksi kran air dengan cara pengecoran tekanan rendah (low pressure die casting) dan menggunakan kuningan $(\mathrm{CuZn})$ sebagai materialnya. Proses ini terus mengembangkan kinerja proses agar didapat kualitas produk yang baik serta waktu dan biaya yang efisien. Keadaan yang sedang terjadi pada industri pengecoran adalah banyaknya cacat pada produk hasil coran, artinya produk tidak bisa digunakan atau harus di lebur ulang dan proses modifikasi dengan cacat yang paling sering terjadi adalah bocor dan hole. Hal ini sangat merugikan perusahaan baik dalam biaya produksi yang menjadi meningkat dan waktu produksi yang semakin lama ${ }^{[1]}$.

Cacat pada logam coran adalah kerusakan atau kesalahan pada logam cor yang mengakibatkan benda cor itu ditolak dari pasaran. Dalam pengecoran cacat tidak dapat dihindari tapi dapat diminimalisir. Cacat pada Low Pressure Die Casting yang terjadi dapat akibatkan pembekuan yang tidak terarah. Cacat yang dapat terjadi adalah hole, shrinkage, porosity, dan distorsi pada mold atau core. Produk kran yang memliki geometri rumit membuat cacat tersebut semakin besar kemungkinan terjadi, karena semakin rumit geometrinya akan semakin sulit juga menentukan arah pembekuan dan kecepatan aliran logam. Melihat hal ini harus dilakukan optimasi proses low pressure die casting yang digunakan dalam pengecoran ${ }^{[2]}$.

Simulasi pengecoran dapat digunakan untuk memecahkan masalah-masalah yang ada di dalam proses pengecoran dan melakukan pengembangan desain tanpa harus mengaplikasikannya secara langsung. Metode ini dinilai sangat efektif dan efisien karena memerlukan waktu yang tidak lama dan biaya yang murah. Pada penelitian ini menggunakan software berbasis FEM (Finite Element Method) yang dapat mengidentifikasi proses pembekuan, shrinkage, cacat lainnya ${ }^{[3]}$.

\section{METODOLOGI}

\section{a.Tahap awal penelitian}

Pada tahap ini akan dilakukan review terhadap produk coran casing kran air, yang meliputi analisis kegagalan cacat coran, analisis komposisi kimia, dan gambar desain. Dari gambar desain casting tersebut kemudian dilakukan simulasi pengecoran dan selanjutnya hasil dari simulasi tersebut dikomparasikan dengan produk coran yang secara aktual.

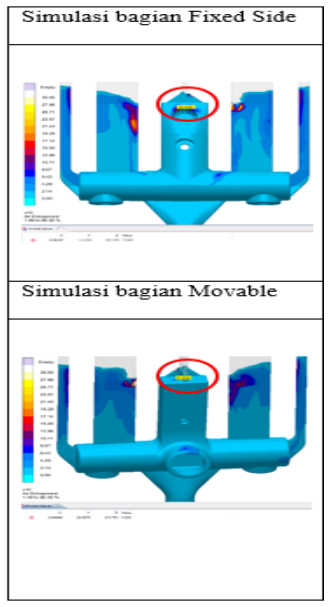

Gambar 1.A

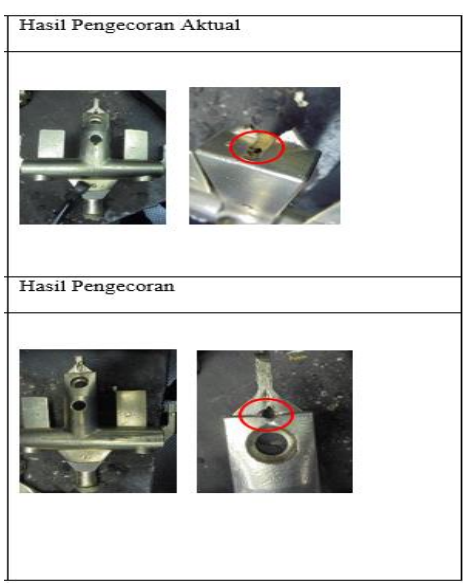

Gambar 1.B

Gambar 1.A menjelaskan bahwa hasil simulasi pada desain awal menggambarkan terjadinya potensi cacat pada bagian ujung cavity dekat area riser. Gambar 1.B menjelaskan bahwa hasil actual pengecoran dari desain awal menggambarkan terjadinya cacat pada bagian ujung cavity dekat area riserb.Tahap penelitian 
Hasil analisis kegagalan cacat coran dan simulasi pengecoran kran digunakan sebagai acuan dalam melakukan perancangan dan simulasi pengecoran casing kran. Proses simulasi pengecoran akan dilakukan beberapa kali sebagai alternatif desain dan dilakukan analisa pemilihan desain untuk dilanjutkan ke proses pengecoran. Kemudian produk coran casing yang telah dicor,dilakukan pengamatan secara visual dan serangkaian pengujian,seperti uji komposisi kimia, untuk justifikasi terhadap kualitas hasil coran dengan membandingkan terhadap standar yang ada.

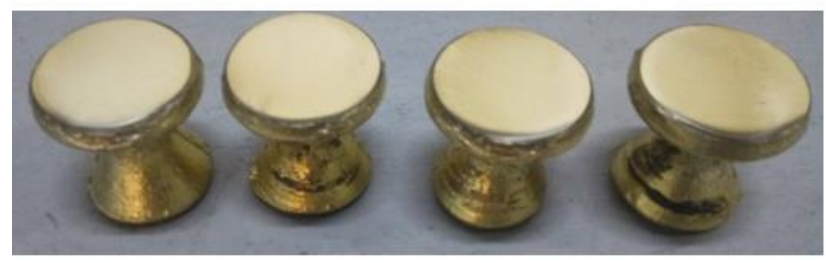

Gambar 2. Sampel uji material Brass Ingot

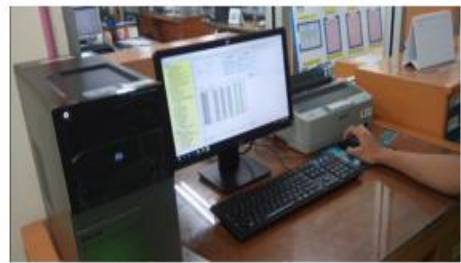

Gambar 3. Komputer untuk input hasil uji komposisi kimia

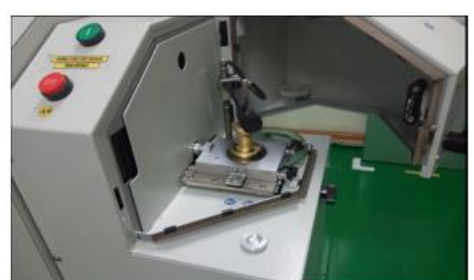

Gambar 4. Mesin Uji Komposisi kimia ( Spectro )

Standar material yang ditetapkan adalah JIS G5151 Grade SCPH2 oleh karena itu komposisi kimia maupun sifat mekanis dari material yang diuji harus masuk dalam spesifikasi yang dipersyaratkan.

Tabel.1. Hasil pengujian komposisi kimia sample Brass Ingot

\begin{tabular}{|c|c|c|c|c|}
\hline No & Kandungan & Standar & Hasil Uji & Keputusan \\
\hline \hline 1 & $\mathrm{Cu}$ & $59.1-61,5$ & 60,0454 & ok \\
\hline 2 & $\mathrm{~Pb}$ & $1,5-2,4$ & 1,7479 & ok \\
\hline 3 & $\mathrm{Fe}$ & $0,03-0,07$ & 0,0554 & ok \\
\hline 4 & $\mathrm{Sn}$ & $<=0,2$ & 0,0137 & ok \\
\hline 5 & $\mathrm{Al}$ & $0,4-0,7$ & 0,5835 & ok \\
\hline 6 & $\mathrm{Zn}$ & Rest & 37,5258 & ok \\
\hline 7 & $\mathrm{Ni}$ & $<=0,2$ & 0,0054 & ok \\
\hline 8 & $\mathrm{Mn}$ & $<=0,01$ & 0,0008 & ok \\
\hline 9 & $\mathrm{Si}$ & $<=0,02$ & 0,0054 & ok \\
\hline 10 & $\mathrm{Cr}$ & $<=0,005$ & 0,0002 & ok \\
\hline 11 & $\mathrm{P}$ & $<=0,01$ & 0,0010 & ok \\
\hline 12 & $\mathrm{Sb}$ & $<=0,06$ & 0,0089 & ok \\
\hline 13 & $\mathrm{Cd}$ & $<=0,03$ & 0,0003 & ok \\
\hline 14 & $\mathrm{~B}$ & $0,0008-0,0012$ & 0,0009 & ok \\
\hline & & & & \\
\hline
\end{tabular}

Dari tabel diatas dapat dilihat bahwa komposisi kimia dari ke empat sample sesuai dengan spesifikasi material JIS G5151 Grade SCPH2. 


\section{HASIL DAN PEMBAHASAN}

\section{Tahap akhir penelitian}

Pada tahap akhir akan diteliti kembali effesiensi biaya pengecoran yang dapat dilakukan (tekno-ekonomi). Kemudian dilanjutkan analisis secara menyeluruh dari penelitian studi kasus pengecoran casting kran ini dan pelaporan seperti terlihat di tabel 1 dan 2 .

Tabel 2. Hasil Simulasi part S11121S
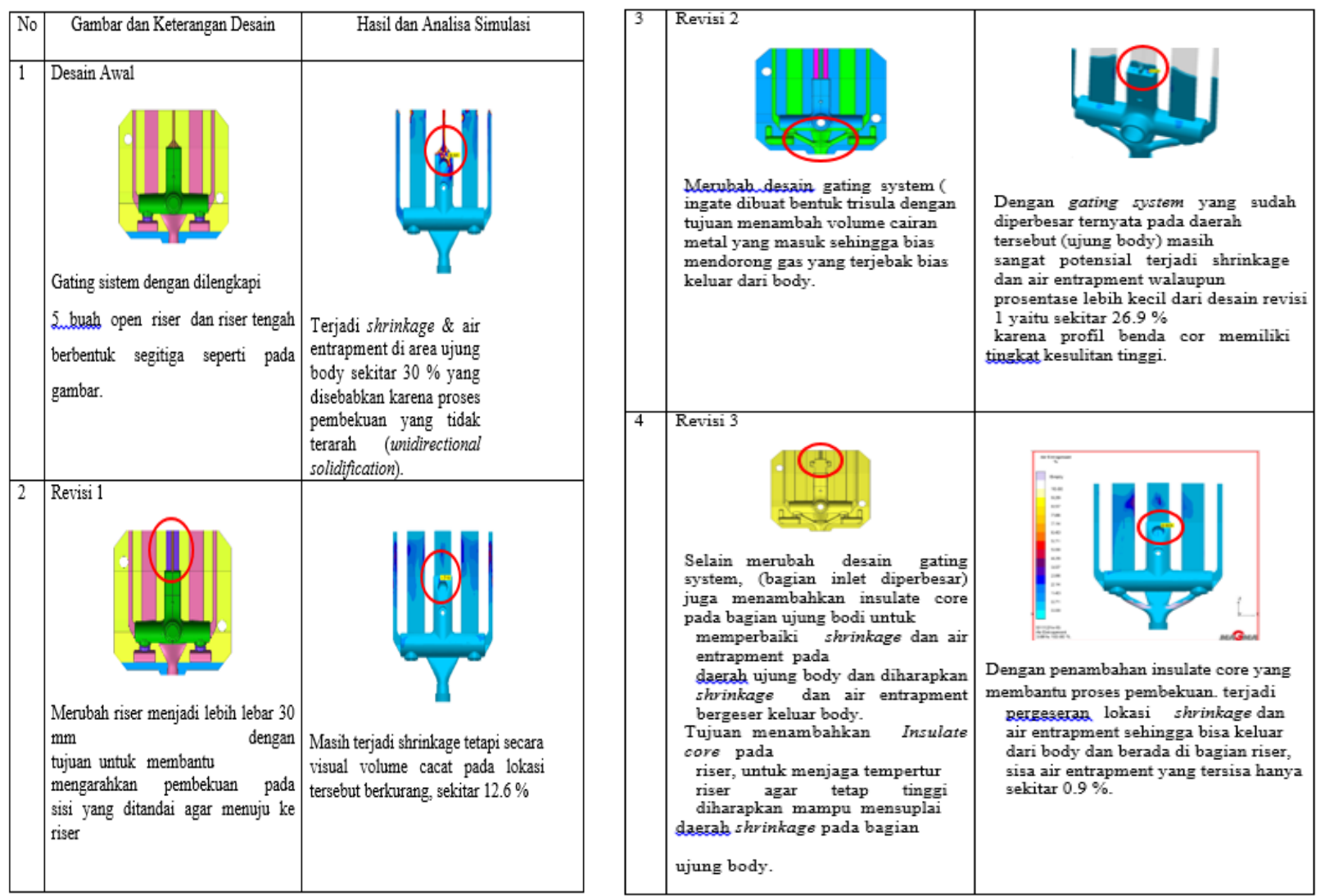
Tabel 3. Analisis dan Pemilihan Desain Mold Casting

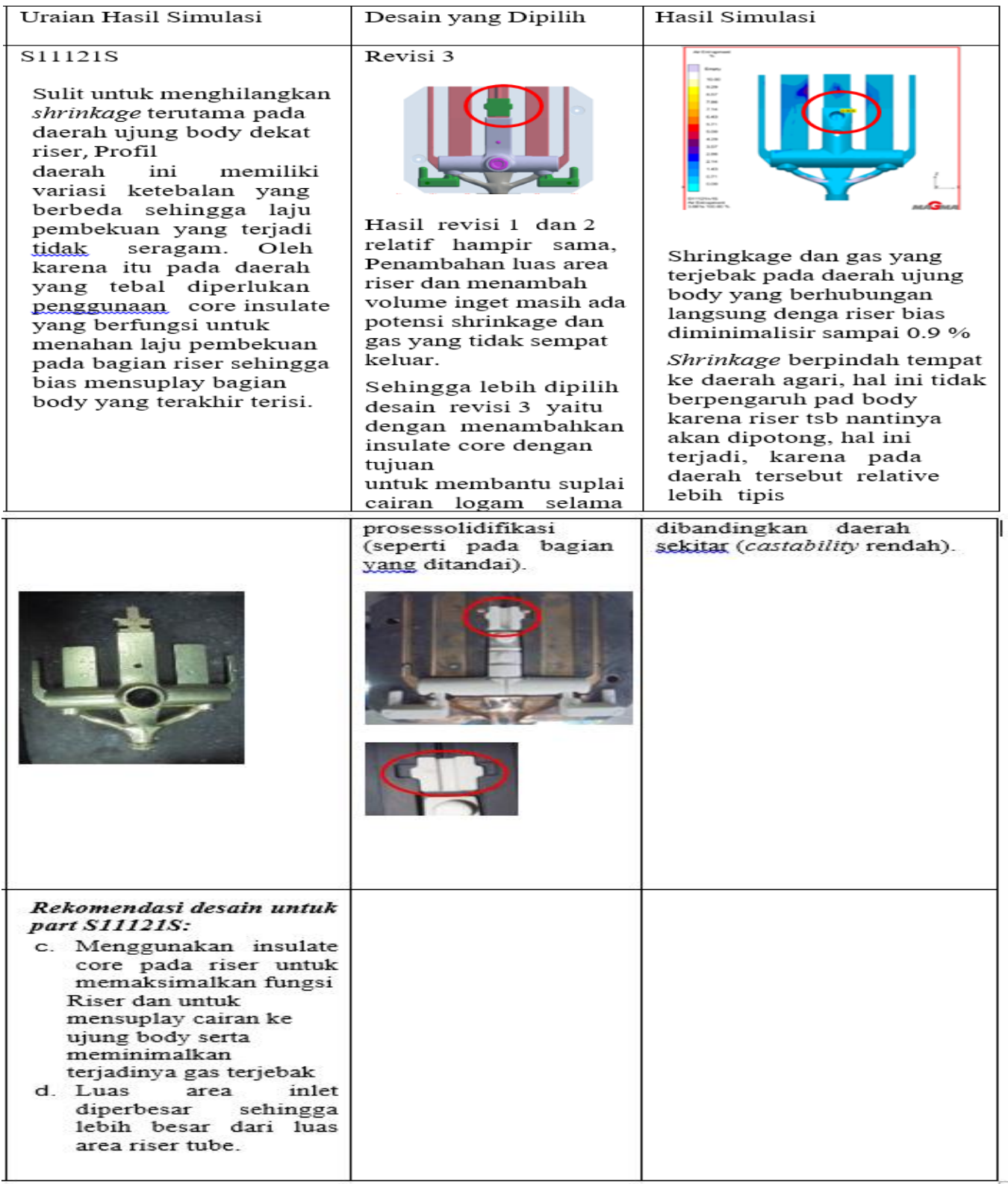




\section{Analisa Kajian Tekno Ekonomi}

A. Efesiensi Waktu dan Cost Perbaikan Mold Casting

Tabel 4. Efesiensi Waktu Perbaikan Mold

\begin{tabular}{|c|c|c|c|c|c|c|c|c|c|}
\hline \multirow[b]{2}{*}{ NO } & \multirow[b]{2}{*}{ ART } & \multirow{2}{*}{$\begin{array}{c}\text { CUP } \\
\text { Mesin } \\
\text { menit }\end{array}$} & \multirow[b]{2}{*}{$\begin{array}{l}\text { Jumlah } \\
\text { Simulasi }\end{array}$} & \multicolumn{2}{|c|}{ Waktu Perbaikan (menit) } & \multirow[b]{2}{*}{$\begin{array}{l}\text { Selisih Waktu } \\
\text { (menit) }\end{array}$} & \multicolumn{2}{|c|}{ Cost perbaikan mold ( $R p)$} & \multirow[b]{2}{*}{$\begin{array}{c}\text { Total Cost } \\
\text { (Rp) }\end{array}$} \\
\hline & & & & $\begin{array}{l}\text { Sebelum } \\
\text { Simulasi }\end{array}$ & $\begin{array}{l}\text { Setelah } \\
\text { Simulasi }\end{array}$ & & $\begin{array}{l}\text { Sebelum } \\
\text { Simulasi }\end{array}$ & $\begin{array}{l}\text { Setelah } \\
\text { Simulasi }\end{array}$ & \\
\hline 1 & $11121 \mathrm{~S}$ & 1634 & 8 & 6,720 & 840 & & $10,980,480$ & $1,372,560$ & $9,607,920$ \\
\hline
\end{tabular}

Dari Tabel diatas dapat dilihat bahwa dengan jumlah simulasi sebanyak 8 kali, selisih waktu perbaikan mold sebanyak 5880 menit ( 98 jam / 4.03 hari ).

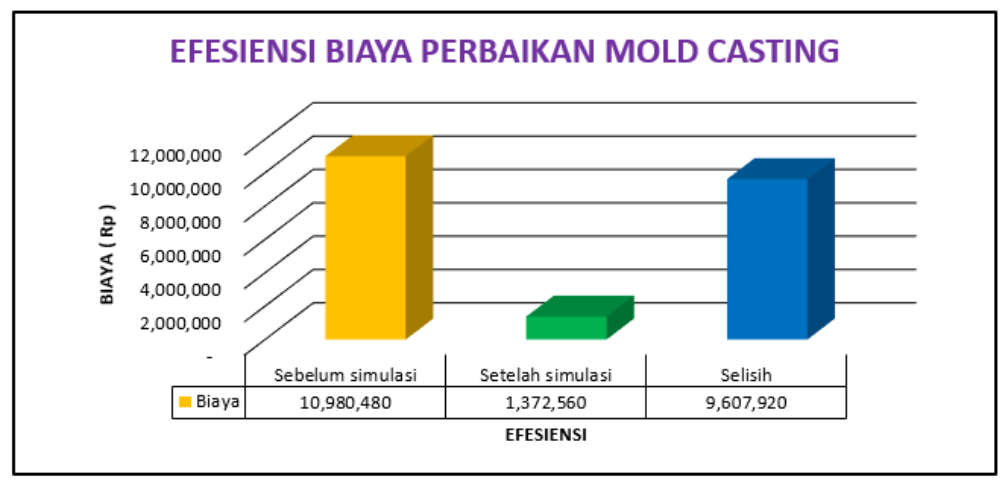

Grafik 1. Efesiensi Biaya Perbaikan Mold

Dari grafik diatas dapat dilihat bahwa dengan adanya simulasi pengecoran, ada efesiensi biaya perbaikan mold casting sebesar Rp. 9.607.920.

B. Efesiensi Waktu Kerja Dengan Simulasi

Tabel 5. Efesiensi Waktu Kerja Dengan Software Simulasi

\begin{tabular}{|c|c|c|c|c|c|c|}
\hline \multirow{2}{*}{$\mathrm{NO}$} & \multirow{2}{*}{ PART } & \multirow{2}{*}{$\begin{array}{l}\text { Jumlah } \\
\text { Running } \\
\text { (A) }\end{array}$} & \multirow{2}{*}{$\begin{array}{c}\text { Kondisi } \\
\text { Lama } \\
\text { (D) } \\
=\mathrm{A} \times \mathrm{Z}\end{array}$} & \multirow{2}{*}{$\begin{array}{c}\text { Kondisi Baru } \\
\text { (hari) } \\
\text { (E) } \\
=\mathrm{Z}+\mathrm{A}\end{array}$} & \multicolumn{2}{|c|}{ Waktu (hari) } \\
\hline & & & & & $\begin{array}{l}\text { Selisih Hari } \\
(\mathrm{G})=\mathrm{D}-\mathrm{E}\end{array}$ & $\begin{array}{l}\begin{array}{l}\text { Percepatan } \\
(\mathrm{H})=\mathrm{D} / \mathrm{E}\end{array} \\
\end{array}$ \\
\hline 1 & S11121S & 8 & 496 & 70 & 426 & 7 \\
\hline
\end{tabular}

Dari Tabel diatas dapat dilihat bahwa dengan jumlah running simulasi sebanyak 8 kali, ada percepatan sebanyak 7 kali.

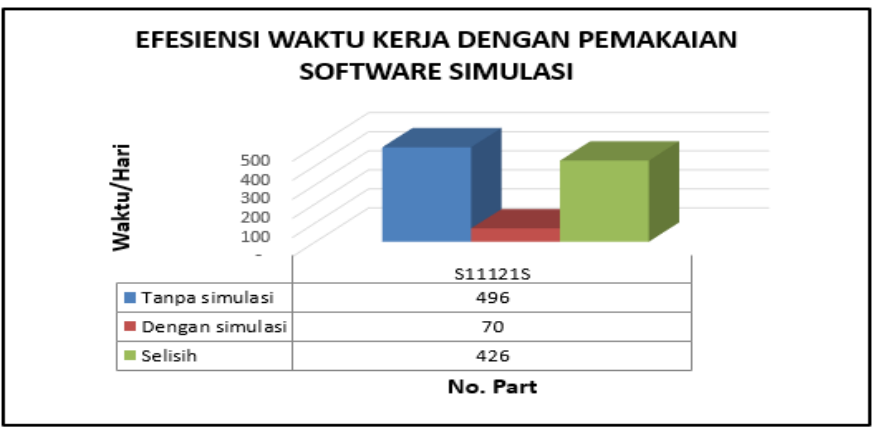

Grafik 2. Efesiensi Waktu Kerja dengan Software Simulasi

Dari grafik diatas dapat dilihat bahwa dengan jumlah running simulasi sebanyak 8 kali, selisih waktu sebanyak 426 hari. 


\section{Efesiensi Cost Reduction Produksi Kran}

Tabel 6. Efesiensi Cost Reduction Kran

\begin{tabular}{|c|c|c|c|c|c|c|c|c|}
\hline \multirow{3}{*}{ No. } & \multirow{3}{*}{ No. Part } & Juni 2016 & \multicolumn{3}{|c|}{ Desember 2016} & Pengurangan & \multirow{2}{*}{ Cost Process } & \multirow{2}{*}{ Cost Reduction } \\
\hline & & $(\% \mathrm{Bad})$ & Prod & Qty Bad & $\% \mathrm{Bad}$ & Jumlah Bad & & \\
\hline & & $a$ & $\mathrm{~b}$ & $\mathrm{c}$ & $\mathrm{d}$ & $\mathrm{e}=(\mathrm{a}-\mathrm{d}) \mathrm{xb}$ & $\mathrm{f}$ & $g=e^{*} f$ \\
\hline 1 & S11121S & 13.22 & 363 & 23 & 6.30 & 25 & 83,368 & $2,094,828$ \\
\hline
\end{tabular}

Dari Tabel diatas dapat dilihat bahwa ada penurunan jumlah prosentase bad dari $13.22 \%$ menjadi $6.3 \%$.

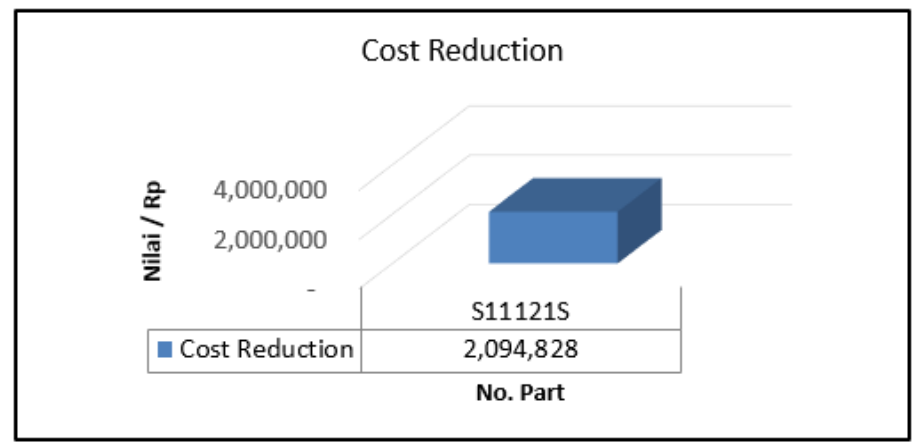

Grafik 3. Efesiensi Cost Reduction Kran

Dari grafik diatas dapat dilihat nilai cost reduction dari part S11121S hasil dari penurunan prosentase bad yaitu sebesar Rp. 2.094.828.

D. Data Perubahan Berat Riser

\begin{tabular}{|c|c|c|c|}
\hline No.Part & Kondisi Awal Riser & Core Insulate & Kondisi Riser setelah penggunaan Insulated \\
\hline \multirow{3}{*}{ S11121S } & & & \\
& & & \\
\hline
\end{tabular}

Gambar.5. Gambar perubahan bentuk Riser sebelum dan sesudah penggunaan Insulated Core

Dari gambar diatas terlihat perubahan bentuk riser setelah penggunaan Insulated core, sehingga ada penambahan berat dari riser tersebut.

Tabel 6. Perubahan Berat Riser Setelah Penggunaan Insulated Core

\begin{tabular}{|c|c|c|c|c|c|c|}
\hline \multirow{2}{*}{ No.Part } & \multicolumn{3}{|c|}{ Berat Riser ( gr ) } & \multirow[b]{2}{*}{ Cost / gr } & \multirow[b]{2}{*}{ Use/m } & \multirow[b]{2}{*}{ Total Cost } \\
\hline & Lama & Baru & Selisih & & & \\
\hline S11121S & 84 & 110 & 26 & 93.63 & 363 & 883,680 \\
\hline
\end{tabular}

Dari Tabel diatas dapat dilihat bahwa ada penambahan berat riser setelah penggunaan Insulated core yaitu sebesar 26 gr sehingga ada penambahan cost sebesar Rp. 883.680. Namun masih dibawah kenaikan cost reduction ( Rp. 2.094.828 ) 


\section{KESIMPULAN}

1. Dari hasil pengujian komposisi kimia yang dilakukan terhadap material $\mathrm{Cu}-\mathrm{Zn}$ dapat disimpulkan bahwa sebagian besar material casing telah sesuai spesifikasi material JIS SCPH2. Untuk kandungan $\mathrm{Pb}$ pada material kran sebesar 1,7\% akan di netralisir pada proses eatching ( sebelum proses plating ), sehingga bisa aman dipergunakan sekalipun untuk konsumsi air minum.

2. Lokasi cacat coran sebagian besar muncul di daerah yang terdapat perbedaan ketebalan secara signifikan, karena daerah ini akan terjadi pebedaan laju pendinginan yang mengakibatkan proses pembekuan sulit untuk diarahkan dan menjadi sangat potensial terbentuk cacat. Sehingga faktor penyebab kegagalan coran casing kran ini karena kesalahan desain coran dan riser kurang berfungsi secara optimal untuk mengkompensasi penyusutan yang terjadi.

3. Dari alternatif desain dan hasil simulasi yang dilakukan didapat hasil sebagai berikut :

a. Desain awal terjadi cacat cor sebesar $=30 \%$

b. Desain Revisi 3 dengan menggunakan insulate core cacat cor sebesar $=0.9 \%$

4. Hasil kualitas coran casing dengan sisem insulate core telah sesuai dengan spesifikasi dan dapat diterima oleh standar ( cacat cor maksimal $5 \%$ ). Sehingga penerapan metode simulasi pengecoran ini mampu mengurangi terjadinya resiko kegagalan dalam pengecoran.

5. Tujuan penambahan insulate core pada riser adalah untuk menjaga temperature riser agar tetap tinggi dan diharapkan mampu mensuplai daerah shrinkage pada bagian ujung cavity dan diharapkan shrinkage bergeser keluar body ( ada pada riser ).

6. Pada tahap akhir penelitian dilakukan perhitungan efesiensi penggunaan software Magma dilihat dari segi efesiensi waktu kerja dengan menggunakan software simulasi, dan segi waktu dan cost dari perbaikan mold casting serta dari segi cost reduction dari perbaikan kualitas kran .

a. Dari segi cost perbaikan mold di workshop

b. Dari segi cost reduction kualitas produksi kran

Total
$=$ Rp. 9.607 .920

= Rp. 2.094 .828

$=$ Rp. 11.702 .748

\section{DAFTAR PUSTAKA}

[1] Bader, Michael. Die Design. Document. KWC Engineering. Unterkulm, 5726, 11 July 2002.

[2] Deni F, Casting Simulation dan Casting Desain, Bahan Ajar DMM-Universitas Indonesia, 2009

[3] Frei, J., Casting Simulation Speed Up Development, Buhler AG, Switzerland, 2005

[4] Polyteknisk Forlag. Fundamental of Numerical Modelling of Casting Processes. 1st. Edited by Jesper Hattel. Lyngby: Polyteknisk Forlag, 2005.

[5] Sadayappan, K., M. Sahoo, and H. T. Michels. "Copper and Copper Alloy Castings." In Casting, Volume 15, ASM Handbook, 1085-1094. Ohio: ASM International, 2008.

[6] Woycik, Gregory G, and Gordon Peters. "Low-Pressure Metal Casting, Casting, Volume 15." In ASM Handbook, by ASM International Handbook Committee, edited by ASM International, 700-708. Ohio: ASM International, 2008. 